\title{
Hyperventilation in the Newborn Piglet Does Not Increase Whole Body Oxygen Consumption as Seen in Mature Animals
}

\author{
JAQUES BELIK AND R. BRUCE LIGHT \\ Departments of Pediatrics and Medicine, University of Manitoba, Winnipeg, Manitoba, Canada
}

\begin{abstract}
Hyperventilation has been shown to cause increased whole body oxygen consumption $\left(\dot{\mathrm{V}} \mathrm{O}_{2}\right)$ and lactic acid production in human and animal mature subjects, but limited data are available in neonates. We investigated the effect of hypocarbic and normocarbic hyperventilation during normoxia and hypoxia (fractional inspired oxygen concentration $=0.14$ ) upon the $\dot{\mathrm{VO}} 2$ in anesthetized and paralyzed piglets. Systemic arterial, pulmonary arterial, and left and right atrial pressures as well as cardiac output and body temperature were continuously recorded. Hypocarbic hyperventilation $\left(\mathrm{PaCO}_{2}=19 \pm 1 \mathrm{~mm} \mathrm{Hg} ; \mathrm{pH}=7.58 \pm\right.$ $0.02)$ was associated with a significant decrease in systemic and pulmonary arterial pressures and cardiac output. These measurements returned to values similar to the initial normoventilation ones when $\mathrm{PaCO}_{2}$ was increased by adding $\mathrm{CO}_{2}$ to the inspired gas, whereas hyperventilation was continued. Neither hyperventilation alone nor in combination with hypoxia induced any significant change in $\dot{\mathrm{VO}}_{2}$. We conclude that in the newborn pig, unlike what has been reported in mature subjects, cellular metabolic function is unaffected by hyperventilation as evidenced by the unchanged $\mathrm{VO}_{2}$. (Pediatr Res 23: 565-568, 1988)
\end{abstract}

\section{Abbreviations}

$\dot{\mathrm{V}} \mathrm{O}_{2}$, whole body oxygen consumption

PPHN, persistent pulmonary hypertension syndrome of the newborn

$\mathrm{FiO}_{2}$, fractional inspired oxygen concentration

iv, intravenous

Hyperventilation is commonly used to treat infants with PPHN (1). Although respiratory alkalosis is a useful treatment modality in this syndrome, much concern has been raised regarding the effect of extreme $\mathrm{pH}$ changes and low $\mathrm{PaCO}_{2}$ on cellular function and metabolism (2).

Active hyperpnea in humans and passive hyperventilation in adult dogs has been shown to cause a significant increase in $\dot{\mathrm{VO}}_{2}$ and lactic acid concentration (3-5). This phenomenon appears to be $\mathrm{pH}$ related and secondary to an increase in muscle oxygen consumption $(6,7)$. Evidence for a similar phenomena in newborns is lacking.

Significant hypoxemia due to shunting across the fetal channels is commonly observed in infants with PPHN and may also influence the $\dot{\mathrm{VO}}_{2}$ in affected newborns. Whereas a significant

Received October 23, 1987; accepted January 26, 1988

Correspondence; Jaques Belik, M.D., Room WR 004, 735 Notre Dame Avenue, Winnipeg, Manitoba R3E 0L8, Canada.

Supported in part by grants from the Children's Hospital of Winnipeg Research Foundation. reduction in $\dot{\mathrm{VO}}_{2}$ has been reported after only moderate hypoxia in ventilated newborn lambs (8), Cameron et al. (9), studying spontaneously breathing and paralyzed newborn lambs after moderate hypoxia, observed a decrease in $\dot{\mathrm{V}} \mathrm{O}_{2}$ only in the mechanically ventilated animals. This latter report suggests that the combination of paralysis and mechanical ventilation may alter the newborn's metabolic response to moderate hypoxia leading to a decrease in $\mathrm{VO}_{2}$.

Neither human nor animal data are available regarding the possible interactive effect of hyperventilation, hypoxia, and paralysis on the newborn's $\mathrm{VO}_{2}$. Inasmuch as hyperventilation is usually prescribed for hypoxemic neonates and often requires the concomitant use of muscle relaxants, it is important to evaluate the interactive effect of these factors on the $\mathrm{VO}_{2}$.

Thus, the purpose herein was to evaluate the effect of hyperventilation with and without hypoxia on the $\dot{\mathrm{VO}}_{2}$ of the paralyzed newborn piglet.

\section{MATERIALS AND METHODS}

Surgical preparation. Camborough piglets kept with the sow until the day of the experiment were anesthetized with pentobarbital sodium $(20 \mathrm{mg} / \mathrm{kg}$ intraperitoneal) and ketamine $(10 \mathrm{mg} /$ $\mathrm{kg}$ intramuscular), and prepared for study as follows. Initially the trachea was cannulated and the animals were connected to a Harvard animal volume ventilator. Pancuronium bromide $(0.2$ $\mathrm{mg} / \mathrm{kg}$ intravenous) was administered and the ventilator settings were adjusted to deliver a fixed tidal volume $(7 \mathrm{ml} / \mathrm{kg})$. The tracheal pressures were measured with a P23 Db Statham pressure transducer from a needle tip positioned near the tracheal end of the endotracheal tube.

Catheters were inserted in the femoral artery and vein and positioned in the abdominal aorta and right atrium, respectively. After a left lateral thoracostomy, the ductus arteriosus was exposed and ligated. A $5 \mathrm{~F}$ polyvinyl catheter was advanced into the pulmonary artery with its tip located immediately proximal to the pulmonary artery bifurcation. A left atrial catheter was inserted via the appendage and a precalibrated electromagnetic flow probe (Carolina Medical Electronics, Inc. King, NC) was placed around the main pulmonary artery to allow for continuous measurement of cardiac output. Care was taken to choose a flow probe size that allowed for good contact with the vessel wall without constricting it. All flow measurements were read from the digital display, with a three digit resolution, when stable. The left chest was covered with a plastic sheet and care was taken to expand the left lung completely. Rectal temperature was monitored continuously (Yellow Springs telethermometer, Yellow Springs Instrument Co., Yellow Springs, $\mathrm{OH}$ ) and maintained at $38.5 \pm 0.5^{\circ} \mathrm{C}$ (normal piglet's temperature) by means of electric heating pads. End tidal $\mathrm{CO}_{2}$ was measured continuously using a Beckman 0M-11 CO $\mathrm{CO}_{2}$ analyzer sampling at the endotracheal level. Anesthesia was maintained by hourly pentobarbital sodium 
administration (3-5 mg/kg iv) and pancuronium bromide ( 0.05 $\mathrm{mg} / \mathrm{kg}$ iv) was repeated when spontaneous breathing was noted. Ketamine was not used as part of the maintenance anesthesia.

After surgery, the animals were allowed a stabilization period of at least $1 \mathrm{~h}$. A positive end expiratory pressure of $3 \mathrm{~cm}$ of water was added to the ventilator to maintain lung inflation and every $30 \mathrm{~min}$ it was increased to $10 \mathrm{~cm}$ of water for $5 \mathrm{~s}$ to prevent lung atelectasis. The catheters were connected to Statham pressure transducers $(\mathrm{P} 23 \mathrm{Db})$ to allow for a continuous recording (Gould multi-channel recorder, Gould Inc., Oxnard, CA) of aortic, pulmonary, and atrial pressure as well as cardiac output, rectal temperature, and airway pressure. Mean pressures were obtained by electrical integration. Arterial blood gas measurements and $\mathrm{pH}$ were made by a microelectrode technique $(0.2 \mathrm{ml}$ of blood) on a model ABL3 Radiometer blood gas analyzer and corrected for the animal's body temperature. Blood oxygen saturation and $\mathrm{Hb}$ were measured in $0.1 \mathrm{ml}$ of blood with a model OSM-2 hemoximeter (Radiometer, Copenhagen, Denmark). Oxygen content was calculated using a value of $1.36 \mathrm{ml}$ of oxygen/g of $\mathrm{Hb}$ as the oxygen-carrying capacity. $\mathrm{V}_{2}$ was calculated as the cardiac output multiplied by the arterial-mixed venous oxygen content difference.

Experimental procedure. Piglets were subjected to three distinct ventilatory patterns in random order as follows. 1) Normoventilation where the ventilator rate was adjusted to maintain normocarbia $\left.\left(\mathrm{PaCO}_{2}=40 \mathrm{~mm} \mathrm{Hg}\right) ; 2\right)$ hyperventilation with hypocarbia where the ventilator rate was increased to lower the $\mathrm{PaCO}_{2}$ below $20 \mathrm{~mm} \mathrm{Hg}$, and 3) hyperventilation with normocarbia where the ventilator rate was maintained, increased, and $\mathrm{CO}_{2}$ was added to the inspiratory port to raise the $\mathrm{PaCO}_{2}$ to the normocarbic range. For each of the above three conditions, the animals were studied on room air and after ventilation with an $\mathrm{FiO}_{2}$ of 0.14 for $10 \mathrm{~min}$ each, for a total of $20 \mathrm{~min}$. In addition, the mean airway pressure was kept unchanged for all conditions by lowering the positive end expiratory pressure as the ventilator rate was increased.

Measurements obtained at each one of the conditions, for a total of six sets, included: systemic, pulmonary, and atrial pressures, cardiac output, heart rate (derived from the pressure tracing), and body temperature. Also, arterial and mixed venous simultaneous blood samples were drawn for $\mathrm{pH}$, blood gases, oxygen saturation, and $\mathrm{Hb}$ determination at the end of each study period, and used to calculate the $\mathrm{VO}_{2}$.

Statistical analysis. Between-condition differences in the mean values for all study parameters were evaluated by analysis of variance for repeated measurements and tested for statistical significance using a multiple comparison test (Duncan's). Statistical significance was taken as $p<0.05$ and all values are represented as mean \pm SEM. We calculated the statistical power of our statistical analysis a posteriori, using the $\mathrm{VO}_{2}$ data obtained during normoventilation normoxia, according to Snedecor and Cochran (10).

\section{RESULTS}

Thirteen animals with a mean age of $5 \pm 1$ days and weight of $1.9 \pm 0.1 \mathrm{~kg}$ were studied. All animals were successfully subjected to all three conditions on air and hypoxia ventilation.

The arterial blood gases, $\mathrm{pH}$, and $\mathrm{Hb}$ concentration are shown in Table 1. Hyperventilation to a mean of $\mathrm{PaCO}_{2}$ of $19 \pm 2 \mathrm{~mm}$ $\mathrm{Hg}$, led to an increase in $\mathrm{pH}$ to $7.58 \pm 0.02$. Hypoxia was associated with an approximately $50 \%$ decrease in $\mathrm{PaO}_{2}$ for all conditions without any significant change in $\mathrm{pH}$ or $\mathrm{PaCO}_{2}$. During normoxic and hypoxic hyperventilation, the $\mathrm{PaO}_{2}$ was higher than normoventilation values, as would be expected with hyperventilation-induced increases in alveolar oxygen tension. In addition, the $\mathrm{Hb}$ concentration was not significantly different for the three study conditions.

Hypocapnic hyperventilation with and without hypoxia induced a significant decrease in systemic and pulmonary arterial pressures and in cardiac output (Table 2). Similar measurements during normocapnic hyperventilation did not reveal any differences as compared to normoventilation values, suggesting that the observed changes were related to $\mathrm{pH}$ and/or $\mathrm{PaCO}_{2}$ alteration.

No significant change in $\dot{\mathrm{VO}}_{2}$ was observed during hyperventilation with or without hypoxia (Table 3 ). The significant increase in arterial and venous oxygen content during hyperventilation was likely due to the alveolar oxygen tension increase. The body temperature, according to the protocol, was similar for all conditions.

\section{DISCUSSION}

Hyperventilation in the newborn anesthetized and paralyzed pig did not change the $\dot{\mathrm{V}}_{2}$, a result that is unlike what has been reported in mature humans (4) and dogs (3, 5-7), but similar to what others have observed in the newborn $\operatorname{dog}(11)$.

It is unlikely that the discordance between results in newborns and those in mature animals results from methodological differences alone. The reported adult animal data involved acute preparations under pentobarbital anesthesia $(3,5-7)$ similar to the present protocol. The duration of hypocarbia in the present experiment was somewhat shorter than that used by other investigators; however, in four of our experiments in which measurements were delayed for as much as $20-25$ min we also saw no difference in $\mathrm{VO}_{2}$. In addition, our results are in accordance with the ones in puppies (11) where the duration of hypocarbia exceeded $2 \mathrm{~h}$. Another methodological consideration is the accuracy of the cardiac output measurements, especially because in newborns there is a potential for flow across the fetal channels leading to inaccurate calculated $\mathrm{V}_{2}$ values. We believe that in the present experiment the measurement of cardiac output by the electromagnetic flow probe around the pulmonary artery was probably identical to the left ventricular output. This assumption

Table 1. Arterial blood gases, $\mathrm{pH}$, and $\mathrm{Hb}$ (mean $\pm S E M)$

\begin{tabular}{|c|c|c|c|c|c|}
\hline & $\mathrm{FiO}_{2}$ & $\mathrm{pH}$ & $\begin{array}{c}\mathrm{PaCO}_{2} \\
(\mathrm{~mm} \mathrm{Hg})\end{array}$ & $\begin{array}{c}\mathrm{PaO}_{2} \\
(\mathrm{~mm} \mathrm{Hg})\end{array}$ & $\begin{array}{c}\mathrm{Hb} \\
(\mathrm{g} / 100 \mathrm{ml})\end{array}$ \\
\hline \multicolumn{6}{|l|}{ Normoventilation } \\
\hline & 0.21 & $7.34 \pm 0.02$ & $39 \pm 1$ & $82 \pm 1$ & $8.8 \pm 0.7$ \\
\hline & 0.14 & $7.33 \pm 0.02$ & $39 \pm 1$ & $37 \pm 2$ & $8.9 \pm 0.8$ \\
\hline \multicolumn{6}{|l|}{ Hyperventilation hypocarbia } \\
\hline & 0.21 & $7.58 \pm 0.02 *$ & $19 \pm 2^{*}$ & $108 \pm 6^{*}$ & $9.1 \pm 0.8$ \\
\hline & 0.14 & $7.60 \pm 0.02^{*}$ & $19 \pm 2 *$ & $63 \pm 4^{*}$ & $9.1 \pm 0.8$ \\
\hline \multicolumn{6}{|l|}{ Hyperventilation normocarbia } \\
\hline & 0.21 & $7.34 \pm 0.02$ & $39 \pm 2$ & $113 \pm 19^{*}$ & $8.9 \pm 0.7$ \\
\hline & 0.14 & $7.33 \pm 0.02$ & $42 \pm 2$ & $57 \pm 3^{*}$ & $8.8 \pm 0.7$ \\
\hline
\end{tabular}

\footnotetext{
${ }^{*} p<0.01$ as compared to normoventilation values.
} 
Table 2. Hemodynamic data (mean \pm SEM)

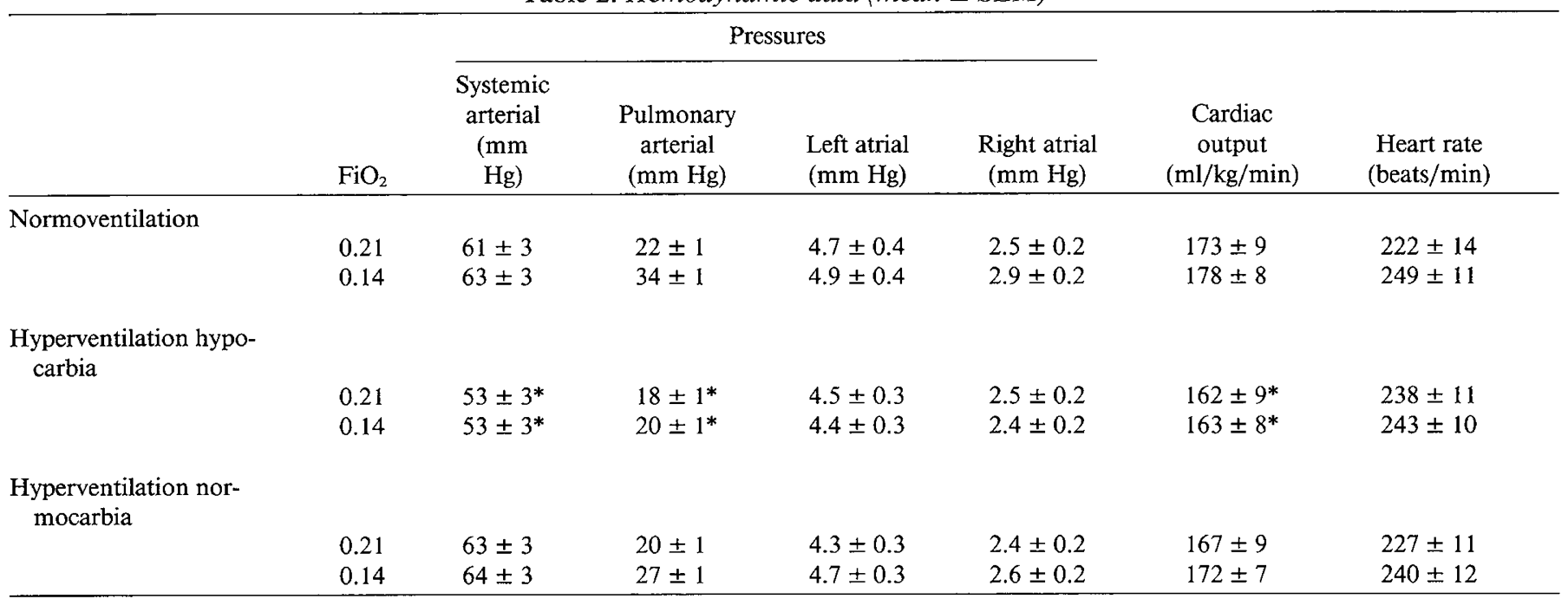

$* p<0.01$ as compared to normoventilation values.

Table 3. Arterial $\left(\mathrm{CaO}_{2}\right)$ and mixed venous $\left(\mathrm{CvO}_{2}\right)$ oxygen content and oxygen consumption $\left(\dot{V} \mathrm{O}_{2}\right)($ mean $\pm S E M)$

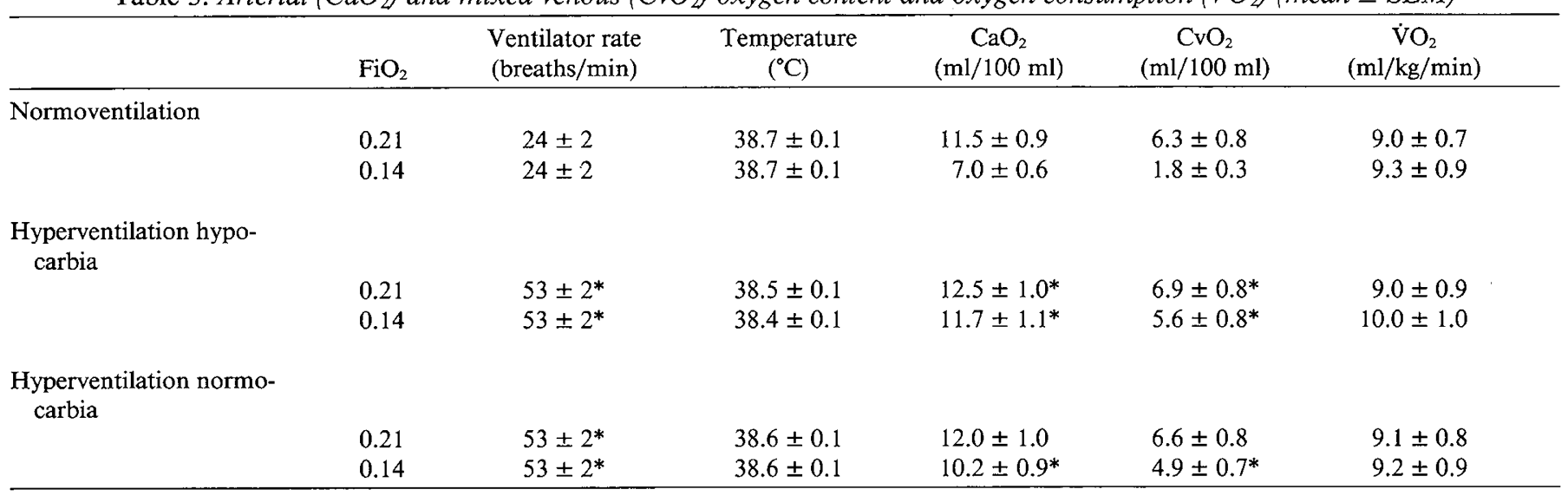

$* p<0.01$ as compared to normoventilation values.

is based on the low likelihood of a significant right to left shunt, given that the ductus arteriosus was ligated in all animals and the left atrial pressure was consistently higher than the right one preventing any shunt at the foramen ovale level. Further, the $\mathrm{VO}_{2}$ calculated from the arterial-venous oxygen content difference and the cardiac output has been shown in the chronically prepared awake newborn pig (12) to yield values similar to the ones obtained by the closed circuit $\dot{\mathrm{VO}}_{2}$ method (13).

Inasmuch as we failed to observe a significant change in $\dot{\mathrm{V}}_{2}$ in the newborn pig during hyperventilation, the possibility of a type-2 error or false-negative results deserve some considerations. Accepting a $\beta$ of 0.20 (power of 0.8 ) and a two tail $\alpha$ of 0.05 the sample size in the present experiment allows for the detection of a $\dot{\mathrm{V}} \mathrm{O}_{2}$ difference of $16 \%$ during normoxic hyperventilation hypocarbia. The sample size of the present experiment was large enough to detect the $20 \%$ average increase in $\mathrm{VO}_{2}$ reported in mature subjects after hyperventilation (3-7).

For all these reasons we believe that our results and those of others (11) are not explicable by methodological differences but represent a real difference between newborns and adults in the $\dot{\mathrm{VO}}_{2}$ response to hyperventilation.

The reason for this difference is not entirely clear. One possibility is related to the major difference in basal $\dot{\mathrm{VO}}_{2}$ between adult and newborn animals. $\mathrm{VO}_{2}$ in newborns is much higher than in adults when indexed to body weight (14). It is conceivable that this higher basal $\dot{\mathrm{VO}}_{2}$ renders any stimulatory effect of increased $\mathrm{pH}$ less important. However, it is also clear that basal
$\dot{\mathrm{VO}}_{2}$ in newborns is still far from maximal $\dot{\mathrm{VO}}_{2}$, as has been demonstrated in studies of cold stress in newborn lambs (15).

Alternatively, differences in activation and maturation of the phosphofructokinase system in newborns could account for the discrepant results. In dogs, the increase in $\mathrm{VO}_{2}$ with hyperventilation has been linked to an observed increase in skeletal muscle metabolism. The proposed mechanism is an increase in glycolysis secondary to activation of phosphofructokinase by the higher intracellular $\mathrm{pH}(6)$, and not the decrease in $\mathrm{PaCO}_{2}$, because alkaline infusion in the adult dogs also increase $\mathrm{VO}_{2}(16)$.

Earlier studies have indicated that total 6-phosphofructo-1kinase activity increases during rat heart and muscle maturation $(17,18)$. Similarly, heart and skeletal muscle in humans have also shown changes in the isoenzyme pool and activity during neonatal development (19). Although data regarding the effect of $\mathrm{pH}$ on the kinetics of muscle phosphofructokinase in newborn animals are not available, we speculate that the activity of this enzyme may not be significantly increased during alkalosis as demonstrated in mature subjects (20). It is also possible that the lesser baseline activity of this enzyme in newborns makes $\mathrm{pH}$ induced changes in activity less important physiologically.

In our study, neither hypoxia $\left(\mathrm{FiO}_{2}=0.14\right)$ nor the combination of hypoxia and hyperventilation induced any significant change in $\mathrm{VO}_{2}$ in the paralyzed piglets. In previous studies, it has been shown that the changes in $\mathrm{VO}_{2}$ with hypoxia are greatly affected by the environmental temperature and the degree of oxygen deprivation to which the newborn animals are subjected 
(15). In human newborns (21-25) and in lambs (26) a significant reduction in $\dot{\mathrm{V}} \mathrm{O}_{2}$ in the absence of a cold stress was only observed when the $\mathrm{FiO}_{2}$ was decreased below 0.12 ; a result not unlike that of Cameron et al. (9) who saw a substantial reduction in the $\mathrm{VO}_{2}$ of the awake and paralyzed lamb after a decrease in $\mathrm{PaO}_{2}$ to 29 $\pm 1 \mathrm{~mm} \mathrm{Hg}$. In the present protocol we used anesthetized and normothermic piglets subjected to a lesser degree of hypoxia, as judged by the $\mathrm{PaO}_{2}$ during hypoxia $(37 \pm 2 \mathrm{~mm} \mathrm{Hg}$ ), than the studies mentioned above. Therefore, differences in protocol design probably accounted for the discrepancy between our results and the ones reported by other investigators on the effect of hypoxia on the $\mathrm{VO}_{2}$ in newborn animals.

In summary, we have observed that unlike adult animals, newborn pigs fail to demonstrate hyperventilation-induced increases in $\mathrm{VO}_{2}$. Differences in the maturation pattern and activity of the glycolytic pathway enzymes during the neonatal period may account for the discrepant results. Further investigation is necessary before the results of our study are extrapolated to infants. Nevertheless, these data suggest that hyperventilationinduced hypocarbia may have less impact on metabolic rate in newborns than has been reported to occur in mature humans and animals.

\section{REFERENCES}

1. Fox WW, Duara S 1983 Persistent pulmonary hypertension in the neonate: diagnosis and management. J Pediatr 103:505-514

2. Bruce DA 1984 Effects of hyperventilation on cerebral blood flow and metabolism. Clin Perinatol 1:673-681

3. Khambatta HJ, Sullivan SF 1973 Effects of respiratory alkalosis on oxygen consumption and oxygenation. Anesthesiology 38:53-58

4. Karetzky MS, Cain SM 1970 Effect of carbon dioxide on oxygen uptake during hyperventilation in normal man. J Appl Physiol 28:8-12

5. Theye RA, Gronert GA, Heffron JJA 1977 Oxygen uptake of canine whole body and hind limb with hypocapnic alkalosis. Anesthesiology 47:416-422

6. Brice AG, Welch HG 1985 Effect of respiratory alkalosis on skeletal muscle metabolism in the dog. J Appl Physiol 58:658-664

7. Cain SM 1970 Increased oxygen uptake with passive hyperventilation of dogs. J Appl Physiol 28:4-7
8. Cross KW, Dawes GS, Mott JC 1959 Anoxia, oxygen consumption and cardiac output in new-born lambs and adult sheep. J Physiol 146:316-343

9. Cameron CB, Gregory GA, rudolph AM, Heymann MA 1986 Cardiovascular effects of D-tubocurarine and pancuronium in newborn lambs during normoxia and hypoxia. Pediatr Res 20:246-252

10. Snedecor GW, Cochran WG 1980 The comparison of two samples. In: Statistical Methods. The Iowa State University Press, Ames, pp 102-105

11. Cartwright D, Gregory GA, Lou H, Heymann HA 1984 The effect of hypocarbia on the cardiovascular system of puppies. Pediatr Res 18:685-690

12. Mayfield SR, Shaul PW, Oh W, Stonestreet B 1987 Anemia blunts the thermogenic response to environmental cold stress in newborn piglets. Pediatr Res 21:482-486

13. Mount LE 1959 The metabolic rate of the newborn pig in relation to environmental temperature and age. J Physiol (Lond) 147:333-345

14. Dawes GS, Mott JC 1959 The increase in oxygen consumption of the lamb after birth. J Physiol 146:295-315

15. Sidi D, Kuipers JRG, Heymann MA, Rudolph AM 1983 Effects of ambient temperature on oxygen consumption and the circulation in newborn lambs at rest and during hypoxemia. Pediatr Res 17:254-258

16. Patterson RW, Sullivan SF 1978 Determinants of oxygen uptake during sodium bicarbonate infusion. J Appl Physiol 45:399-402

17. Baldwin KM, Hooker AM, Campbell PJ, Lewis RE 1978 Enzyme changes in neonatal skeletal muscle effect of thyroid deficiency. Am J Physiol 235:C97$\mathrm{C} 102$

18. Baldwin KM, Cooke DA, Cheadle WG 1977 Enzyme alterations in neonatal heart muscle during development. J Mol Cell Cardiol 9:651-660

19. Kahn A Cottreau D Dreyfus JC 1980 Phosphofructokinase in human fetus. Pediatr Res 14:1162-1167

20. Trived B, Danforth WH 1966 Effect of pH on the kinetic of frog muscle phosphofructokinase. J Biol Chem 10:4110-4114

21. Oliver TK, Karlberg P 1963 Gaseous metabolism in newly born human infants. Am J Dis Child 105:39-47

22. Adamsons K Jr 1959 Breathing and the thermal environment in young rabbits. J Physiol 149:144-153

23. Cross KW, Tizard JPM, Trythall DAH 1958 The gaseous metabolism of the new-born infant breathing 15\% oxygen. Acta Paediatr 47:217-237

24. Cross KW, Flynn DM, Hill JR 1966 Oxygen consumption in normal newborn infants during moderate hypoxia in warm and cool environments. Pediatrics 37:565-576

25. Hill, JR 1959 The oxygen consumption of new-born and adult mammals. Its dependence on the oxygen tension in the inspired air and on the environmental temperature. J Physiol 149:346-373

26. Moss M, Morean G, Lister G 1987 Oxygen transport and metabolism in the conscious lamb. The effects of hypoxemia. Pediatr Res 22:177-183 